\title{
Supersensitivity by AF64A, a Novel Inhibitor of Neuronal Choline-Uptake, of the Rat Iris Sphincter Smooth Muscle
}

\author{
Masako TANAKA, Natsuki S. Yamahara, Junko KondoH, \\ Michino Furuta, Yuji Imaizumi* and Minoru Watanabe \\ Department of Chemical Pharmacology, and *Department of Pharmacology \\ and Therapeutics, Faculty of Pharmaceutical Sciences, Nagoya City University \\ Nagoya 467-8603, Japan
}

\begin{abstract}
Effects of ethylcholine mustard aziridinium ion (AF64A) on contractile responses to agonists or transmural nerve stimulation (TNS) were examined in rat iris sphincter muscle. The responses to TNS of isolated sphincter muscle were abolished within $1 \mathrm{hr}$ after the addition of $0.1 \mathrm{mM} \mathrm{AF64A}$ to the bathing solution, while responses to acetylcholine (ACh) and 5-hydroxytryptamine (5-HT) were not changed significantly. In sphincter muscles which were isolated 3 days after the micro-injection of $100 \mathrm{nmol} \mathrm{AF64A}$ into the anterior chamber of eyes in vivo, the response to TNS were decreased to about $30 \%$ of the control. The injection of AF64A at higher concentrations often resulted in serious chronic damage of the eye. When $100 \mathrm{nmol}$ AF64A was injected twice with an interval of 3 days, the response to TNS was decreased to about $20 \%$ of the control. Maximum responses and sensitivities to ACh and 5-HT were markedly enhanced in sphincters from eyes which had been treated with AF64A twice. The sensitivity of depolarized sphincters to external $\mathrm{Ca}^{2+}$ was also increased significantly. Seven weeks after the second injection, responses to TNS recovered to more than $50 \%$ of the control and the effects of AF64A mostly disappeared. In conclusion, the acute inhibition of parasympathetic transmission without postsynaptic changes can be achieved within $1 \mathrm{hr}$ after bath-application of $0.1 \mathrm{mM} \mathrm{AF64A}$. The reduction of parasympathetic nerve activity by treatment with AF64A in vivo induces nonspecific supersensitivity in iris sphincter, whereas effects of AF64A were mostly reversible under the present experimental conditions.
\end{abstract}

Key words : iris sphincter muscle, AF64A, parasympathetic nerve, denervation supersensitivity, muscarinic receptor

\section{Introduction}

The iris sphincter muscle of the rat is innervated densely by parasympathetic nerves (Csillik and Koelle, 1965 ; Huhtala et al., 1976 ; Narita and Watanabe, 1981) and also by sensory nerves of trigeminal origin having substance P-like immunoreactivity (Miller et al., 1981;

Correspondence to: M. Watanabe, Department of Chemical Pharmacology, Faculty of Pharmaceutical Sciences, Nagoya City University, 3-1 Tanabe-dori, Mizuhoku, Nagoya 467-8603, Japan.

Phone : 052-836-3431 Fax : 052-836-3431 e-mail : mwatanab@phar.nagoya-cu.ac.jp 
Shimizu, 1982 ; Kessler, 1985). The parasympathetic transmission in the muscle is characteristic of its electrical features, since the contraction induced by acetylcholine, which is released from nerve endings or added externally, is triggered by neither depolarization nor action potential in sphincter smooth muscle cells (Banno et al., 1985, Imaizumi et al., 1984). This indicates that the transmission is mediated by a typical pharmaco-mechanical coupling (Somlyo et al., 1999).

Denervation is an excellent strategy to investigate the modulation of postsynaptic membranes in smooth muscle cells by the autonomic nerves (Westfall, 1981; Akhtar and AbdelLatif, 1986). Since most of parasympathetic ganglia are located in the target organs, the surgical denervation is not practical except for a few organs. Surgical parasympathetic denervation of iris smooth muscle can be performed by ciliary ganglionectomy and results in specific and non-specific supersensitivities to ACh and the other agonists $\left(5-\mathrm{HT}\right.$ and high- $\mathrm{K}^{+}$ solution), respectively, in the sphincter (Hasegawa et al., 1987 ; Banno et al., 1987) or the dilator (Hasegawa et al., 1988; Hashimoto et al., 1993). The chemical sympathetic denervation using 6-hydroxydopamine (Kostrzewa and Jacobowitz, 1975) or guanethidine (Burnstock et al., 1971 ; Shibata et al., 1989) and the depletion of noradrenaline in sympathetic nerve endings using reserpine (Trendelenburg and Gravenstein, 1958; Zaimis, 1961) have been giving advantages to clarify neuronal controls of tissue functions by both central and peripheral sympathetic nerves. These have also been widely used as standard pharmacological methods removing or decreasing the influence of sympathetic innervation in experimental preparations. Substances which effectively and selectively degenerate parasympathetic nerves or reduce acetylcholine content in nerve endings have not been developed. Although hemicholinium has been known as a choline-uptake inhibitor in cholinergic nerve endings (Gylys et al., 1992), our preliminary study indicated that the compound may not be effective in the rat iris sphincter to reduce responses to nerve stimulation.

AF64A has been introduced as a selective cholinotoxin to produce a chemically induced models of central cholinergic nerve deficit including Alzheimer's disease in rats (Fisher and Hanin, 1980 ; Hanin, 1996). An injection of the compound to cerebral ventricle gives irreversible damages to central cholinergic neurons, resulting in the reduction of the biochemical markers such as choline acetyltransferase activity and choline uptake (Walsh et al., 1984) and the facilitation of the activation of phosphoinositide turnover or the cAMP accumlation elicited by muscarinic receptor agonist (Eva et al., 1987). Although some usefulness of AF64A as a choline-uptake inhibitor has been suggested in smooth muscle tissues such as ileum, urinary bladder (Hoyle et al., 1986) and colon (Hoyle et al., 1986; Hata et al., 1990), tissue-specific application of AF64A in vivo is not feasible. While a decrease in activity of choline acetyltransferase in the rat iris after treatment with AF64A has been demonstrated (Kessler, 1985), functional changes in iris muscles have not been examined yet. The present study was undertaken to evaluate $\mathrm{AF} 64 \mathrm{~A}$ as a pharmacological tool to reduce or abolish ACh release from parasympathetic nerve endings and to perform chemical denervation of parasympathetic nerves in a smooth muscle tissue. 


\section{Materials and Methods}

\section{Preparation and recording of mechanical responses}

Eyes were excised from male Wistar rats (300 to $500 \mathrm{~g}$ ), which have been anesthetized and killed by bleeding. Iris sphincter preparation and tension measurement were made as described in detail in a previous paper (Narita and Watanabe, 1981). Briefly, whole sphincter was dissected as a ring preparation by cutting dilator muscle. An isolated preparation from an eye treated with AF64A (left) or contralateral eye (right) was horizontally mounted in a $4 \mathrm{ml}$ organ bath and perfused with a bathing solution. One side of the sphincter was pinned on a sheet of silicone rubber which formed the bottom of the bath. The other side was fixed to a transducer lever. At the start of an experiment, resting tone was adjusted to $50 \mathrm{mg}$.

Isometric tension was measured with a strain gage transducer (Imaizumi and Watanabe, 1983) and recorded on a pen-recorder (FBR 252A, TOA Electronics Ltd., Japan). Transmural nerve stimulation (TNS) was performed by field stimulation via a pair of platinum wire electrodes which were placed at both sides of the strip. Square-wave pulses of $0.2 \mathrm{msec}$ in duration were applied for $5 \mathrm{sec}$ at $20 \mathrm{~Hz}$ in frequency. The current intensity for TNS was decided as about $10 \%$ excess of that giving the maximum response which is completely blocked by tetrodotoxin in the control sphincter muscles. A dose-response curve to a drug was determined by cumulative addition of a drug to the bathing solution under the conditions where the perfusion of the solution was stopped. A concentration-response curve to $\mathrm{Ca}^{2+}$ was determined in the same manner. Effects of high $\mathrm{K}^{+}$solution were examined by changing a perfusion solution to the high $\mathrm{K}^{+}$solution.

\section{Treatment with AF64A}

For application of AF64A in vivo, rats were anesthetized with an i.p. injection of thiopental sodium $(25 \mathrm{mg} / \mathrm{kg}$ ) and amobarbital sodium $(50 \mathrm{mg} / \mathrm{kg})$. Injection of AF64A into the anterior chamber of the eye was performed by slow injection of $1 \mathrm{mM}, 10 \mathrm{mM}$ or $20 \mathrm{mM}$ AF64A in 10 $\mu \mathrm{l}$ saline (10,100 or $200 \mathrm{nmol}$, respectively) using sterilized Hamilton syringe and 26 gage injection needle. After certain period from the injection, eyes were dissected and irides were used for the tension measurement. In some experiments, eyes were injected with vehicle alone in the same manner and used for control experiments.

\section{Solution}

The bathing solution was a modified Krebs' solution of the following composition (mM) : $\mathrm{NaCl}$ 112.0, $\mathrm{KCl}$ 4.7, $\mathrm{CaCl}_{2} 2.2, \mathrm{MgCl}_{2}$ 1.2, $\mathrm{NaHCO}_{3}$ 25.0, $\mathrm{KH}_{2} \mathrm{PO}_{4}$ 1.2, and glucose 14.0. The solution was bubbled with $95 \% \mathrm{O}_{2}$ and $5 \% \mathrm{CO}_{2}$ and kept at $37^{\circ} \mathrm{C}$ and $\mathrm{pH}$ 7.4. High potassium solution was prepared by replacing $\mathrm{NaCl}$ in the modified Krebs' solution with equimolar $\mathrm{KCl}$ and by adding $1 \mu \mathrm{M}$ atropine and $1 \mu \mathrm{M}$ phentolamine. To prepare high $\mathrm{K}^{+}, \mathrm{Ca}^{2+}$-free solution, $\mathrm{CaCl}_{2}$ was removed from high $\mathrm{K}^{+}$solution and $100 \mu \mathrm{M}$ EGTA was added.

AF64A was prepared as previously described by Fisher et al. (1982). AF64A was formed by dissolving ethylcholine mustard (AF64) hydrochloride in $0.9 \% \mathrm{NaCl}$ (physiological saline) and adjusting the $\mathrm{pH}$ to 7.4 with solid $\mathrm{NaHCO}_{3}$. The solution was kept at room temperature 
for at least $1 \mathrm{hr}$. The obtained AF64A solution was kept on ice and was used within $5 \mathrm{hrs}$ from the $\mathrm{pH}$ adjustment.

\section{Drugs}

The following drugs were used; ethylcholine mustard (AF64) hydrochloride (Research Biochemical International, Natick, MA, USA), acetylcholine chloride (ACh, Wako, Japan), 5hydroxytryptamine creatine sulfate (5-HT, Wako, Japan), atropine sulfate (Atr, Wako, Japan), phentolamine mesylate (Phent, Ciba-Geigy, Japan), glycoletherdiaminetetraacetic acid (EGTA, Dojin, Japan).

\section{Statistics}

Results were expressed as mean \pm S.E. Statistical significance between two or multiple groups was tested according to paired $t$-test or one-way ANOVA, respectively, $(p<0.05,0.01$ or 0.001 ) and $\mathrm{p}$ levels are represented $\mathrm{by}^{*, * *}$, and ${ }^{* * *}$, respectively.

\section{Results}

1) Effects of $A F 64 A$ added in vitro on contractile responses of the rat iris sphincter muscles

Rat iris sphincter muscle exhibits contractile responses to ACh which is either released from cholinergic nerve endings by TNS or exogenously applied (Narita and Watanabe, 1981). When AF64A at the final concentration of $0.1 \mathrm{mM}$ was added to the bathing solution, the perfusion was stopped. The solution was continuously oxygenated, circulated and kept at $37^{\circ} \mathrm{C}$ in the bath. Responses to TNS of a sphincter muscle were recorded for about $3 \mathrm{hrs}$. The amplitude of control responses to TNS in the absence of AF64A (only vehicle was added) was

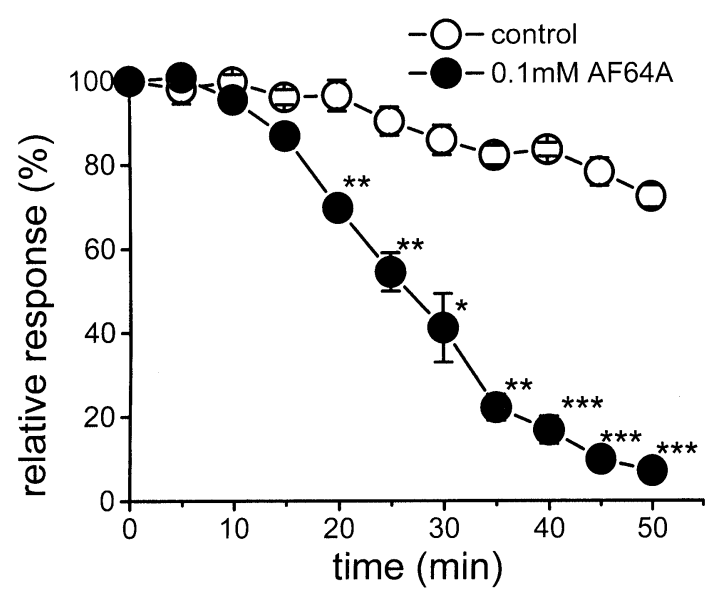

Fig. 1. Effects of AF64A on the time course of relative contractile response to transmural nerve stimulation ( $0.2 \mathrm{msec}$ in duration, $20 \mathrm{~Hz}$ in frequency). The amplitude of contraction elicited by TNS was normalized with that before the application of saline (open circle) or AF64A (closed circle). Values are means \pm S.E. Numbers of experiments are shown in the parentheses. S.E. were often smaller than the symbols. ${ }^{*},{ }^{* *}$, or ${ }^{* * *}$ indicates statistical significance vs. control at $p<0.05,0.01$ or 0.001 , respectively. 
consistent for 20-30 min and thereafter decreased gradually (Fig. 1). On the other hand, the responses of sphincter muscles challenged with AF64A progressively declined and almost abolished within $1 \mathrm{hr}$. The abolished response to TNS did not recover by washout for over 2 hrs (not shown, $n=3$ ). Three hours after the start of experiments, the amplitude of responses to TNS in the control was about $70 \%$ of the initial one (not shown). Even after the response to TNS abolished in the presence of AF64A, the response to exogenously applied ACh was not significantly affected. The maximum response to and $\mathrm{pD}_{2}$ values of $\mathrm{ACh}$ in the control $(1 \mathrm{hr}$ after the application of vehicle) were $49.2 \pm 4.9 \mathrm{mg}$ and $5.21 \pm 0.13$, respectively ( $n=4$ for each), and those in the presence of $0.1 \mathrm{mM} \mathrm{AF} 64 \mathrm{~A}$ were $37.9 \pm 9.9 \mathrm{mg}$ and $5.31 \pm 0.18$, respectively $(n=$ 4 for each; $p>0.05$ vs. control).

2) Effects of AF64A applied in vivo on contractile responses of the rat iris sphincter muscles Effects of treatment with AF64A in vivo by micro-injection into the anterior chamber of the eye on contractile responses of isolated iris sphincter muscle were examined in the next series of experiments. Since it has been reported that application of $10 \mathrm{nmol}$ AF64A into anterior chamber of the eye in the rat results in marked death of cholinergic neurons (Kessler, 1985), we first examined effects of $10 \mathrm{nmol} A F 64 \mathrm{~A}$ on iris sphincter. In the preliminary experiments, however, this amount $(10 \mathrm{nmol})$ of application only slightly decreased the response to TNS (by about 20\%) approximately $24 \mathrm{hrs}$ after the injection. Of interest was that the maximum responses to ACh and 5-HT tended to increase (ACh : 125.1 $14.8 \%$ of the control, $n=4, p>0.05 ; 5-\mathrm{HT}: 154.7 \pm 13.2 \%$ of the control, $n=4, p<0.05$ ) (Fig. 2 ), whereas the sensitiv-

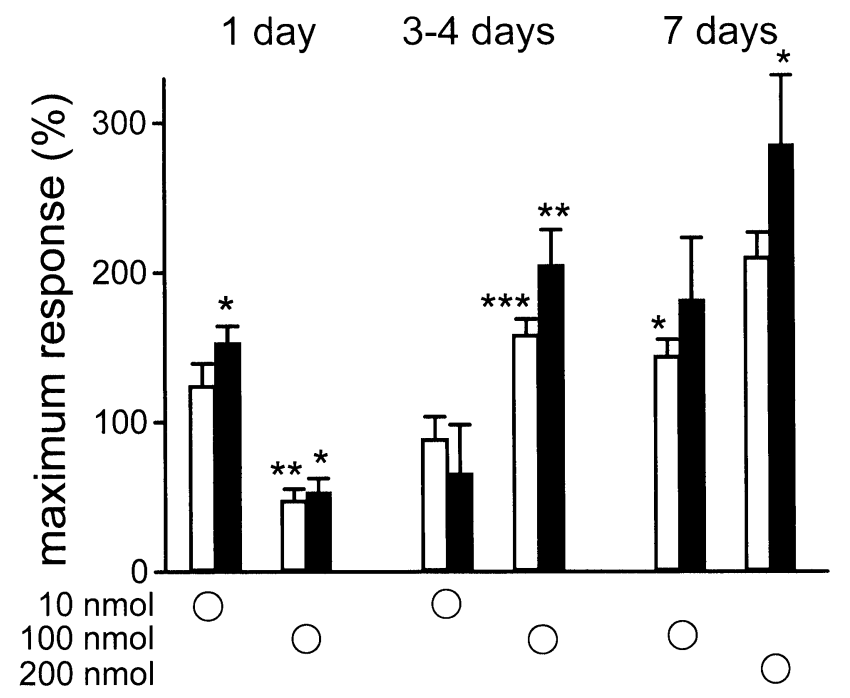

Fig. 2. Maximum responses to ACh (open columns) and 5-HT (closed columns) of iris sphincters from eyes treated with 10, 100 or $200 \mathrm{nmol}$ AF64A. Eyes were isolated one day (approximately $24 \mathrm{hrs}$ ), three or four days or seven days after the injection of AF64A. The maximum responses to $1 \mathrm{mM}$ ACh and $10 \mu \mathrm{M} 5$-HT of the sphincter obtained from the contralateral eye in each rat were taken as the control (100\%). The injected amounts of AF64A were indicated by circles below the columns. Numbers of experiments are 4-5, 710 and 4 for 10,100 and $200 \mathrm{nmol}$, respectively. ${ }^{*},{ }^{* *},{ }^{* * *}$ indicate statistical significance vs. control at $p<0.05,0.01$ and 0.001 , respectively. 
ities were not changed $\left(\mathrm{pD}_{2}\right.$ values of $\mathrm{ACh}$ : control $=5.10 \pm 0.04, \mathrm{AF} 64 \mathrm{~A}=5.11 \pm 0.10 ; \mathrm{pD}_{2}$ values of $5-\mathrm{HT}$; control $=6.61 \pm 0.05, \mathrm{AF} 64 \mathrm{~A}=6.46 \pm 0.06, n=4$ for each, $p>0.05$ ). On the $3 \mathrm{rd}$ day from the injection, responses to TNS recovered to a similar extent to those in the control and both the maximum responses and sensitivities to $\mathrm{ACh}$ and $5-\mathrm{HT}$ in AF64A-pretreated sphincters were not significantly different from those in the control.

Since marked changes in contractile responses were not found after the injection of $10 \mathrm{nmol}$ AF64A, effects of larger amounts of AF64A were examined. Based on the results of experiments to determine the upper limit of the amount of AF64A for one injection, it was found that $100 \mathrm{nmol}$ was practically close to the limit which did not make serious chronic or subchronic damages in whole eyes in most of experiments (>80\%). Injection of $200 \mathrm{nmol} \mathrm{AF64A} \mathrm{resulted}$ in opaque eyes in about $40 \%$ of treatment and the loss of stiffness of irides. Fig. 2 summarizes the maximum responses to ACh (open column) and 5-HT (closed column) of iris sphincters from eyes treated with 10, 100 or $200 \mathrm{nmol}$ AF64A. The maximum contraction in a sphincter from the contralateral eye was taken as the unit in each rat. One day after the injection of $100 \mathrm{nmol}$ AF64A, the maximum response was significantly smaller than the control. However, three or four days after the injection, the responses became significantly larger than the control. The responses to TNS of sphincters treated with $100 \mathrm{nmol}$ AF64A were significantly smaller than the control $(34.0 \pm 17.3 \%$ of the control, $n=4, p<0.05)$, whereas the extent of decrease varied widely from preparation to preparation. When eyes were not damaged by the injection of 200 $\mathrm{nmol} \mathrm{AF} 64 \mathrm{~A}$, the maximum responses of sphincters were measured 7 days after the injection and tended to be larger than those in sphincters treated with $100 \mathrm{nmol}$ AF64A.

The application of $100 \mathrm{nmol} \mathrm{AF} 64 \mathrm{~A}$, which appeared to be the upper limit of the dose to minimize nonspecific damages, was not enough to induce chronic inhibition of parasympathetic transmission in iris sphincter. Therefore, another addition of $100 \mathrm{nmol}$ AF64A was performed on the third day after the first injection. Since each application of $100 \mathrm{nmol} \mathrm{AF} 64 \mathrm{~A}$ induced irreversible damage at the probability of $10-20 \%$, the third application was not examined systematically in this study. In sphincter muscles isolated on the fourth day after the second injection, the responses to TNS were significantly smaller than the control $(47.5 \pm 11.1 \%$ of the control, $n=10, p<0.001$ vs. control), but surprisingly tended to be larger than those in sphincters treated with AF64A once $(34.0 \pm 17.3 \% p>0.05)$. Fig. $3 \mathrm{~A}$ shows that dose-response relationships to exogenously applied ACh in the control and AF64A-treated sphincter muscles isolated on the 4 th day after the second injection. Fig. $3 \mathrm{~B}$ and $\mathrm{C}$ show the time course after the second injection of the changes in maximum response to $1 \mathrm{mM} \mathrm{ACh}$. The maximum responses of sphincter muscles isolated 4, 21 and 49 days after the second injection were $213.8 \pm 16.8,256.8 \pm$ 41.6 and $137.4 \pm 24.5 \%$ of the control, respectively, and indicating that the change was still reversible. Fig. $3 \mathrm{~B}$ shows changes in $\mathrm{pD}_{2}$ values with time after the second injection, and indicates that the increased sensitivity to ACh after 4 days gradually returned to the control level. It is clear that the increase in the maximum response and sensitivity to ACh was larger than those in sphincter muscles treated once. After 3 and 7 weeks, the maximum responses of AF64A-treated sphincters were $144.5 \pm 14.4 \%$ (not shown, $n=3, p<0.05$ vs. $100 \%$ ) and $105.4 \pm$ $36.0 \%$ of the control (not shown, $n=3, p>0.05$ vs. $100 \%$ ), respectively, indicating that the effects of AF64A disappeared between 3 and 7 weeks. 

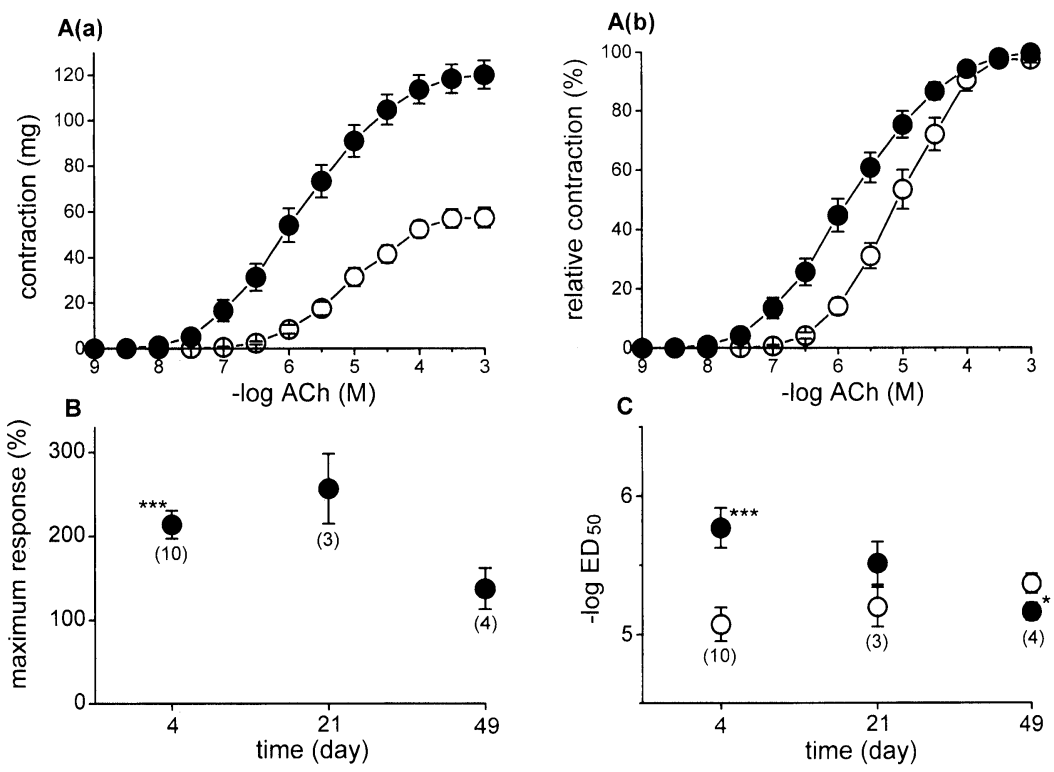

Fig. 3. A : Dose-response relationships for exogenously applied ACh in the control (open circle) and sphincter muscles isolated on the 4th day after the second treatment with AF64A (closed circle). The number of experiments is 10 . In $\mathrm{A}(\mathrm{b})$, responses were expressed as relative percentage of each maximum response in $\mathrm{A}(\mathrm{a}) .{ }^{*},{ }^{* *},{ }^{* * *} ; p<0.05,0.01$ or 0.001 vs. control, respectively. B: The time course of changes in maximum responses induced by $1 \mathrm{mM}$ ACh after the second treatment. Response was normalized with each maximum response of contralateral iris sphincter $(100 \%)$. The numbers in parentheses indicate the numbers of irides used. The numbers in abscissa indicate the days after the second injection. ${ }^{*},{ }^{* * *} ; p<0.05$ or 0.001 vs. $100 \%$, respectively. C: The time course of changes in $\mathrm{pD}_{2}$ values of $\mathrm{ACh}$-induced responses (control ; open circle, AF64A ; closed circle) after the second injection. ${ }^{* *} ; p<0.01$ vs. control. Values are means \pm S.E.

Similar results were obtained when changes in the response to 5-HT were examined after the second injection (Fig. 4). The increase in the maximum response to 5 - $\mathrm{HT}$ was, however, larger than that to $\mathrm{ACh}$. The sensitivity to $5-\mathrm{HT}\left(\mathrm{pD}_{2}: 6.81 \pm 0.09, n=4\right)$ was significantly higher than the control $(6.49 \pm 0.04, n=4)$ only on the 4 th day after the injection. After 3 and 7 weeks, the maximum responses were $153.2 \pm 2.6 \%$ (not shown, $n=3, p<0.01$ vs. $100 \%$ ) and $129.0 \pm 19.3 \%$ (not shown, $n=3, p>0.05$ vs. $100 \%$ ), respectively.

Fig. 5 illustrates the time-courses of relative amplitude of responses to TNS after the first or second injection of $100 \mathrm{nmol} \mathrm{AF64A.} \mathrm{Taking} \mathrm{the} \mathrm{changes} \mathrm{in} \mathrm{muscle} \mathrm{contractility} \mathrm{after} \mathrm{the}$ treatment into account, the ordinate is expressed as a relative amplitude calculated in the following manner.

Relative amplitude $(\%)=($ Response to TNS of a treated sphincter/Response to TNS of the control sphincter $) \times($ Maximum response to $\mathrm{ACh}$ of the control sphincter/Maximum response to ACh of a treated sphincter $) \times 100$

Even after this correction, the remaining response to TNS was about $20 \%$ of the control on the 4 th day after the second injection. Since over $97 \%$ of the remaining component is blocked by $1 \mu \mathrm{M}$ atropine, contamination of tachykininergic component or direct activation of the muscle can be negligible. These results suggest that substantial cholinergic transmission 

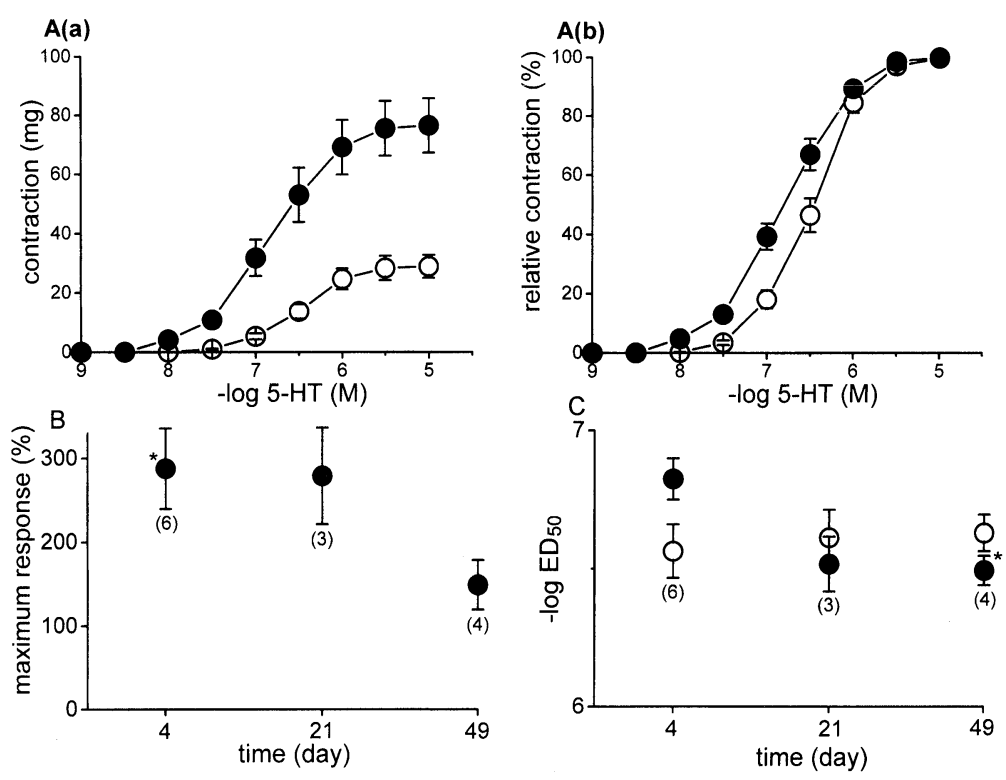

Fig. 4. A : Dose-response relationships for exogenously applied 5-HT in the control (open circle) and sphincter muscles isolated on the 4th day after the second treatment with AF64A (closed circle). The number of experiments is 6 . In $A(b)$, responses were expressed as relative percentage of each maximum response in $\mathrm{A}(\mathrm{a})$ in the same manner as in Fig. 2. *, ${ }^{* *} ; p<0.05$ or 0.01 vs. control, respectively. B : The time course of changes in maximum responses induced by $10 \mu \mathrm{M} 5-\mathrm{HT}$ after the second treatment. Response was normalized with each maximum response of contralateral iris sphincter, taken as $100 \%$. The numbers in parentheses indicate the numbers of irides used. The numbers in abscissa indicate the days after the second injection. ${ }^{*},{ }^{* *} ; p<0.05$ or 0.01 vs. $100 \%$, respectively. $\mathrm{C}$ : The time course of $\mathrm{pD}_{2}$ values of 5 -HT-induced responses (control; open circle, AF64A; closed circle). Values are means \pm S.E.

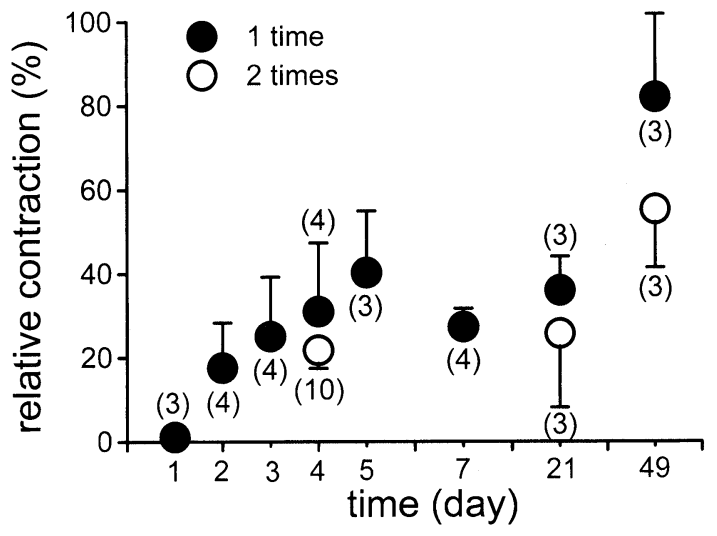

Fig. 5. The time course of relative contractile responses induced by TNS after the first (closed circle) or second (open circle) injection of $100 \mathrm{nmol}$ AF64A. The numbers in abscissa indicate the days after the first or second injection of AF64A. Relative responses were normalized as follows ; Relative amplitude (\%)=(Response to TNS of a treated sphincter/ Response to TNS of the control sphincter) $\times$ (Maximum response to ACh of the control sphincter/Maximum response to ACh of a treated sphincter) $\times 100$. The numbers in the parentheses are numbers of irides used. Values are means \pm S.E. 

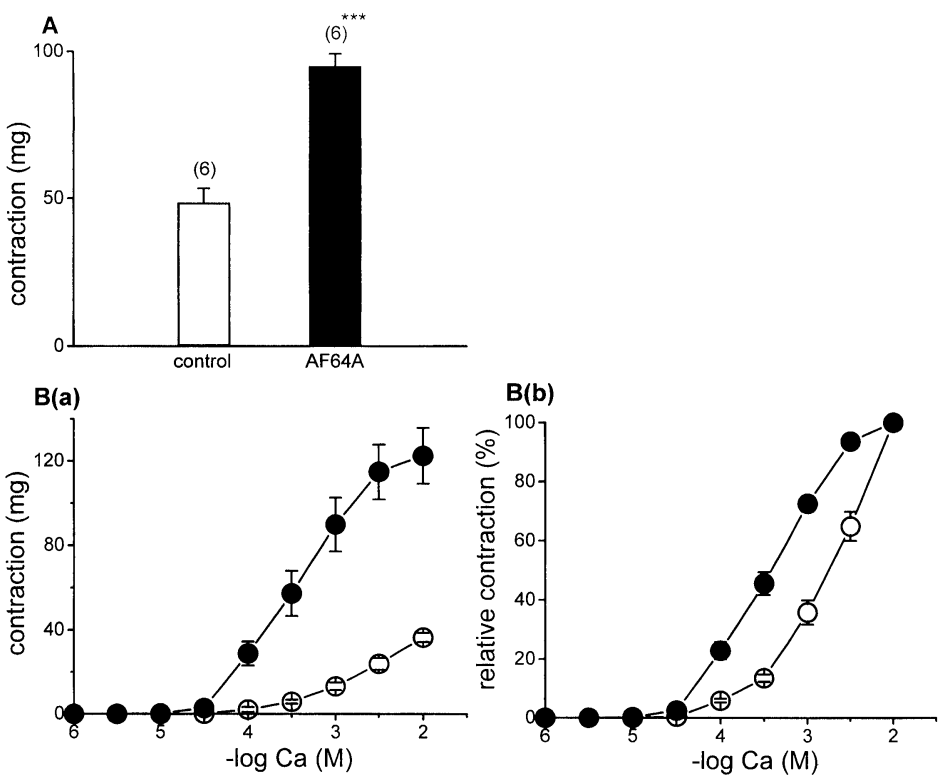

Fig. 6. A : Effects of AF64A on contractile response induced by $80 \mathrm{mM}$ high potassium of the control sphincter muscles (open column) and those isolated on the 4th day after the second injection (solid column). Eighty millimolar $\mathrm{NaCl}$ was replaced with equimolar $\mathrm{KCl}$ to keep the osmolarity of the solutions constant. The solution contained $1 \mu \mathrm{M}$ atropine and phentolamine. Note that AF64A markedly increased the contraction induced by $80 \mathrm{mM}$ $\mathrm{K}^{+}$.

B : Effects of AF64A on contractile response elicited by cumulative application of calcium to high $\mathrm{K}^{+}$solution which did not contain $\mathrm{Ca}^{2+}\left(80 \mathrm{mM}\right.$ high $\mathrm{K}^{+}, \mathrm{Ca}^{2+}$-free solution). $\mathrm{B}(\mathrm{a})$ shows absolute value of contraction amplitude $(\mathrm{mg})$ induced by addition of $\mathrm{Ca}^{2+}$. In $\mathrm{B}(\mathrm{b})$, the response was expressed as relative percentage of maximum response in $\mathrm{B}(\mathrm{a})$ in each preparation. Open circle; control, closed circle; AF64A-treated sphincters isolated on the 4 th day after the second injection. Values are means \pm S.E. ${ }^{*},{ }^{* *}$, and, ${ }^{* * *}$ indicate statistical significance vs. control at $p<0.05,0.01$, and 0.001 , respectively.

remained after the treatment with AF64A. The decreased response to TNS appeared to recover partly after 7 weeks.

\section{3) Non-specific supersensitivity induced by AF64A}

The most significant change in sphincter muscles after the treatment with AF64A was the increase in the maximum responses to $\mathrm{ACh}$ and 5 - $\mathrm{HT}$, suggesting the nonspecific increase in responses to agonists. To confirm whether the response to high $\mathrm{K}^{+}$which may not involve sensitization of contractile system to $\mathrm{Ca}^{2+}$ is changed by the treatment with $\mathrm{AF} 64 \mathrm{~A}$ or not, effects of $80 \mathrm{mM} \mathrm{K}^{+}$were examined in the control and AF64A-treated sphincters (Fig. 6A). The response to $80 \mathrm{mM} \mathrm{K}^{+}$solution was increased by about $100 \%$ in sphincters isolated 4 th day after the second injection.

In addition, the contraction induced by adding $\mathrm{Ca}^{2+}$ to a high $\mathrm{K}^{+}, \mathrm{Ca}^{2+}$-free solution was markedly increased in sphincters pretreated with AF64A twice (Fig. 6Ba). It is notable that the sensitivity to extracellular $\mathrm{Ca}^{2+}$ as well as the maximum response is significantly increased in irides pretreated with $\mathrm{AF} 64 \mathrm{~A}$ (Fig. 6Bb). 


\section{Discussion}

The results obtained from experiments applying $0.1 \mathrm{mM}$ AF64A in vitro clearly indicate that parasympathetic transmission was suppressed by the treatment within $1 \mathrm{hr}$. Of importance is that the effect was not removed by washout for over $2 \mathrm{hrs}$ and that the responses to externally applied ACh and 5-HT were not affected. Acute treatment with AF64A in vitro may possibly be a useful pharmacological method to suppress parasympathetic transmission without causing significant postsynaptic influence in isolated tissues.

In preceded works, it has been shown that intraperitoneal application of AF64A at doses close to or over $\mathrm{LD}_{50}$ to the guinea-pig results in partial decrease in contractile responses in skeletal muscle to motornerve stimulation and in smooth muscles of ileum, urinary bladder and colon to TNS (Hoyle et al., 1986). Although the increase in sensitivities to ACh and carbachol has been found in ileum, the increase in maximum responses by AF64A has not been reported in any smooth muscle preparation. From these results, it has been concluded that i.p. application of AF64A is not useful for the selective degeneration of parasympathetic nerves (Hoyle et al., 1986). In contrast, it has been reported that the actions of AF64A are irreversible in the mouse hippocampus (Fisher and Hanin, 1980) and result in cholinergic hypofunction (Hanin, 1990). In rat iris, it has been reported that the cholinergic nerve degeneration as decrease in choline acetyltransferase has been induced by an injection of $10 \mathrm{nmol} \mathrm{AF64A}$ into the anterior chamber (Kessler, 1985). The local application of AF64A performed in the present study may have, therefore, a great advantage similar to that in central nervous system. This research is the first report showing marked functional changes of smooth muscle induced by AF64A.

The volume of anterior chamber of human eye is approximately $210 \mu 1$ (Johnson et al., 1978). Supposing that the ratio between the size of eye and the volume of anterior chamber is similar in various animals, the volume in the rat may be approximately $11 \mu \mathrm{l}$. The concentration of AF64A in the anterior chamber just after the injection of $10 \mathrm{nmol} / 10 \mu 1 \mathrm{AF} 64 \mathrm{~A}$ can be, therefore, assumed as $\sim 480 \mu \mathrm{M}$. The aqueous humor in the anterior chamber of the human eye is exchanged in approximately $2 \mathrm{hrs}$, while the exchange rate depends upon the intraocular pressure. If it is also the case in the rat, the concentration of AF64A progressively declined to about $180 \mu \mathrm{M}$ after 2 hrs. Although $180 \mu \mathrm{M}$ AF64A in vitro is almost enough to inhibit parasympathetic transmission, $10 \mathrm{nmol} \mathrm{AF} 64 \mathrm{~A}$ added in vivo did not affect significantly the transmission. Moreover, the treatment with $100 \mathrm{nmol}$ AF64A decreased the transmission significantly but not abolished it. Even when eyes were injected with $100 \mathrm{nmol}$ AF64A twice with interval of 3 days, the transmission was neither abolished. The increase in maximum contractility and sensitivity to ACh by the injection of AF64A partly masks the pronounced decrease in amount of stored ACh in parasympathetic nerve endings. Moreover, the decreased transmission by injection of AF64A in vivo recovered significantly after several weeks. Since $100 \mathrm{nmol}$ AF64A was close to the upper limit to inject into the chamber, complete parasympathetic denervation in iris sphincter muscle by AF64A injection in vivo appeared to be difficult to perform.

The most striking finding in the present study is that the intraocular injection of $\mathrm{AF} 64 \mathrm{~A}$ induced a typical postsynaptic supersensitivity, which is characterized by extraordinary non- 
specific features. It is notable that not only the maximum response to high $\mathrm{K}^{+}$but also the sensitivity to extracellular $\mathrm{Ca}^{2+}$ was markedly increased. These are exactly the same as the results obtained by parasympathetic denervation by ciliary ganglionectomy (Hasegawa et al., 1987). The mechanisms, however, underlying the nonspecific supersensitivity by the AF64A injection were not further examined in the present study. The increase in availability of $\mathrm{Ca}^{2+}$ has been reported in vas deferens of the guinea-pig after sympathetic denervation (Kasuya et al., 1969). An increase in the sensitivity of the contractile proteins by a change in the activity or amount of calmodulin has been proposed to explain the supersensitivity induced by the sympathetic denervation (Ramos et al., 1986). Similar possibility has been suggested in parasympathectomized iris sphincter or dilator (Hasegawa et al., 1987; Banno et al., 1987 ; Hashimoto et al., 1993). Further experiments are required, especially using skinning techniques, to elucidate the mechanisms for AF64A-induced nonspecific supersensitivity.

\section{Acknowledgements}

Watanabe, M. and Imaizumi, Y. are supported by a Grant-in-Aid for Scientific Research from the Japanese Ministry of Education, Science and Culture.

\section{References}

Akhtar, R.A. and Abdel-Latif, A.A. (1986). Surgical sympathetic denervation increases alpha 1adrenoceptor-mediated accumulation of myo-inositol trisphosphate and muscle contraction in rabbit iris dilator smooth muscle. J. Neurochem. 46, 96-104.

Banno, H., Imaizumi, Y. and Watanabe, M. (1985). Pharmaco-mechanical coupling in the response to acetylcholine and subsatnce $\mathrm{P}$ in the smooth muscle of the rat iris sphincter. Br. J. Pharmacol. 85, 905-911.

Banno, H., Imaizumi, Y. and Watanabe, M. (1987). Cellular mechanisms of supersensitivity to acetylcholine and potassium ion after ciliary ganglionectomy in the rat iris sphincter muscle. Jpn. J. Pharmacol. 43, 153-163.

Burnstock, G., Evans, B., Gannon, B.J., Heath, J.W. and James, V. (1971). A new method of destroying adrenergic nerves in adult animals using guanethidine. Br. J. Pharmacol. 43, 295-301.

Csillik, B. and Koelle, G.B. (1965). Histochemistry of the adrenergic and the cholinergic innervation apparatus as represented by the rat iris. Acta Histochem. 22, 350-363.

Eva, C., Fabrazzo, M. and Costa, E. (1987). Changes of cholinergic, noradrenergic and serotonergic synaptic transmission indices elicited by ethylcholine aziridinium ion (AF64A) infused intraventricularly. J. Pharmacol. Exp. Ther. 241, 181-186.

Fisher, A., Mantione, C.R., Abraham, D.J. and Hanin, I. (1982). Long-term central cholinergic hypofunction induced in mice by ethylcholine aziridinium ion (AF64A) in vivo. J. Pharmacol. Exp. Ther. 222, 140-145.

Gylys, K.H., Mellin, C., Amstutz, R. and Jenden, D.J. (1992). Characterization of the irreversible inhibition of high-affinity choline transport produced by hemicholinium mustard. J. Neurochem. 59, 1302-1308.

Hanin, I. (1990). AF64A-induced cholinergic hypofunction. Prog. Brain Res. 84, 289-299.

Hanin, I. (1996). The AF64A model of cholinergic hypofunction: an update. Life Sci. 58, 1955-1964.

Hasegawa, N., Imaizumi, Y. and Watanabe, M. (1987). Parasympathetic denervation supersen- 
sitivity in the rat iris sphincter muscle: an in vitro study. Jpn. J. Pharmacol. 43, 143-151.

Hasegawa, N., Imaizumi, Y. and Watanabe, M. (1988). Parasympathetic denervation abolishes acetylcholine-induced relaxation in the rat iris dilator. Eur. J. Pharmacol. 156, 291-294.

Hashimoto, Y., Hasegawa, N., Suzuki, N., Kawai, T., Imaizumi, Y. and Watanabe, M. (1993). Effects of ciliary ganglionectomy on contractile responses in the dilator muscle of the rat iris. Exp. Eye Res. 56, 135-141.

Hata, F., Kataoka, T., Takeuchi, T., Yagasaki, O. and Yamano, N. (1990). Differences in control of descending inhibition in the proximal and distal regions of rat colon. Br. J. Pharmacol. 101, 1011-1015.

Hoyle, C.H.V., Moss, H.E. and Burnstock, G. (1986). Ethylcholine mustard aziridinium ion (AF64A) impairs cholinergic neuromuscular transmission in the guinea-pig ileum and urinary bladder, and cholinergic neuromodulation in the enteric nervous system of the guinea-pig distal colon. Gen. Pharmacol. 17, 543-548.

Huhtala, A., Tervo, T., Huikuri, K.T. and Palkama, A. (1976). Effects of denervations on the acetylcholinesterase-containing and fluorescent nerves of the rat iris. Acta Ophthalmol. 54, 85-98.

Imaizumi, Y., Banno, H. and Watanabe, M. (1984). Anomalous stabilizing action of Ca on sphincter smooth muscle of the rat iris. Pfiugers Arch. 400, 332-334.

Imaizumi, Y. and Watanabe, M. (1983). Effect of 4-aminopyridine on potassium permeability of canine tracheal smooth muscle cell membrane. Jpn. J. Pharmacol. 33, 201-208.

Johnson, S.B., Coakes, R.L. and Brubaker, R.F. (1978). A simple photogrammetric method of measuring anterior chamber volume. Am. J. Ophthalmol. 85, 469-474.

Kasuya, Y., Goto, K., Hashimoto, H., Watanabe, H., Munakata, H. and Watanabe, M. (1969). Nonspecific denervation supersensitivity in the rat vas deferens in vitro. Eur. J. Pharmacol. 8, 177-184.

Kessler, J.A. (1985). Parasympathetic, sympathetic, and sensory interactions in the iris: nerve growth factor regulates cholinergic ciliary ganglion innervation in vivo. J. Neurosci. 5, 2719-2725.

Kostrzewa, R.M. and Jacobowitz, D.M. (1975). Pharmacological actions of 6-hydroxy dopamine. Pharmacol. Rev. 26, 199-288.

Miller, A., Costa, M., Furness, J.B. and Chubb, I.W. (1981). Substance P immunoreactive sensory nerves supply the rat iris and cornea. Neurosci. Letts. 23, 243-249.

Narita, S. and Watanabe, M. (1981). Response of the isolated rat iris sphincter to cholinergic and adrenergic agents and electrical stimulation. Life Sci. 29, 285-292.

Ramos, K., Gerthoffer, W.T. and Westfall, D.P. (1986). Denervation-induced supersensitivity to calcium of chemically skinned smooth muscles of the guinea-pig vas deferens. J. Pharmacol. Exp. Ther. 236, 80-84.

Shibata, K., Takei, S., Kawai, T., Imaizumi, Y. and Watanabe, M. (1989). Decrease in neuronal uptake of noradrenaline simply explains the supersensitivity after sympathectomy in the rat iris dilator. Jpn. J. Pharmacol. 50, 19-29.

Shimizu, Y. (1982). Localization of neuropeptides in the cornea and uvea of the rat: An immunohistochemical study. Cell Mol. Biol. 28, 103-110.

Somlyo, A.P., Wu, X., Walker, L.A. and Somlyo, A.V. (1999). Pharmacomechanical coupling: the role of calcium, G-proteins, kinases and phosphatases. Rev. Physiol. Biochem. Pharmacol. 134, 201-234.

Trendelenburg, U. and Gravenstein, J.S. (1958). Effect of reserpine pretreatment on stimulation of the accelerans nerve of the dog. Science 128, 901-902.

Walsh, T.J., Tilson, H.A., DeHaven, D.L., Mailman, R.B., Fisher, A. and Hanin, I. (1984). AF64A, a cholinergic neurotoxin, selectively depletes acetylcholine in hippocampus and cortex, and 
produces long-term passive avoidance and radial-arm maze deficits in the rat. Brain Res. 321, 91-102.

Westfall, D.P. (1981). Supersensitivity of smooth muscle. In : Smooth Muscle, Edited by Bülbring, A.F., Jones, A.W. and Tomita, T., pp. 85-309, Edward Arnold, Ltd., London.

Zaimis, E. (1961). Reserpine-induced circulatory failure. Nature 192, 521-532.

(Received September 29, 1999 : Accepted December 21, 1999) 